\title{
Sophisticated band pass filters by PARMS technology for the 3MI project
}

\section{Andreas Rahm, Marc Lappschies, Stefan Jakobs, David Blum, Federico La China, et al.}

Andreas Rahm, Marc Lappschies, Stefan Jakobs, David Blum, Federico La China, Carmine Alessio Mastrandrea, Barbara Grandclaude, Marie-Noëlle Langevin, Massimiliano Porciani, "Sophisticated band pass filters by PARMS technology for the 3MI project," Proc. SPIE 11852, International Conference on Space Optics - ICSO 2020, 1185210 (11 June 2021); doi:

$10.1117 / 12.2599290$

SPIE Event: International Conference on Space Optics - ICSO 2021, 2021, Online Only 


\section{International Conference on Space Optics-ICSO 2020}

Virtual Conference

30 March-2 April 2021

Edited by Bruno Cugny, Zoran Sodnik, and Nikos Karafolas
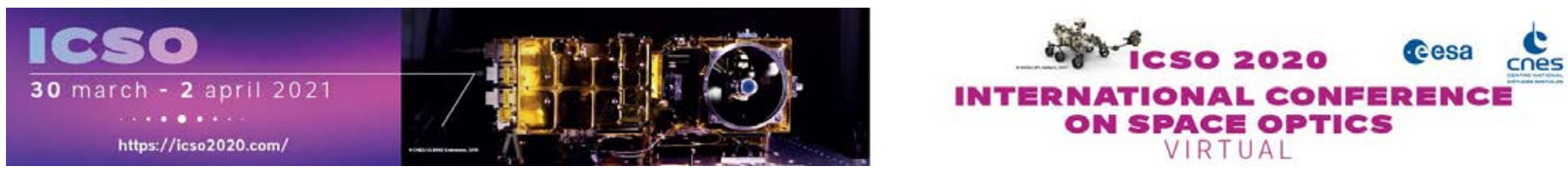

\section{Sophisticated band pass filters by PARMS technology for the 3MI project}

\section{- esa issopocestings denes}




\title{
Sophisticated band pass filters by PARMS technology for the 3MI project
}

\author{
Andreas Rahm *a, Marc Lappschies a , Stefan Jakobs ${ }^{\mathrm{a}}$, David Blum ${ }^{\mathrm{b}}$, Federico La China ${ }^{\mathrm{c}}$, Carmine \\ Alessio Mastrandrea ${ }^{\mathrm{c}}$, Barbara Grandclaude ${ }^{\mathrm{d}}$, Marie-Noëlle Langevin ${ }^{\mathrm{d}}$, Massimiliano Porciani ${ }^{\mathrm{e}}$ \\ ${ }^{a}$ Optics Balzers Jena GmbH, Otto-Eppenstein-Straße 2, 07745 Jena, Germany \\ ${ }^{\mathrm{b}}$ RUAG Schweiz AG, RUAG Space, Schaffhauserstrasse 580, 8052 Zürich, Switzerland \\ ${ }^{\mathrm{c}}$ LEONARDO, Società per azioni, Via delle Officine Galileo 1, IT - 50013 Campi Bisenzio (FI) \\ d Airbus Defence and Space / ADS, 31 rue des Cosmonautes, 31402 Toulouse, Cedex 4 (France) \\ e ESA/ESTEC, Keplerlaan 1, 2200 AG Noordwijk, The Netherlands
}

\begin{abstract}
The Multi-viewing, Multi-channel, Multi-polarisation Imager (3MI) is one of the instruments of the "Satellite A" payload of MetOp-SG, developed to provide information on atmospheric aerosols. 3MI is a space based, wide-field-ofview spectroradiometer that is designed to acquire sequential images of the same ground target which are combined with multiple spectral views in both un-polarized and polarized channels. The spectral coverage in the multiple bands from $410 \mathrm{~nm}$ to $910 \mathrm{~nm}$ and from $910 \mathrm{~nm}$ to $2130 \mathrm{~nm}$ shall be done using a Filter Wheel Assembly which included the Filter Wheel Disk (FWD). OBJ was selected for development and production of these optical elements. This contribution addresses the manufacturing and characterization of the demanding dielectric optical coatings for the sophisticated BPFs developed by Optics Balzers.
\end{abstract}

Keywords: coating, PARMS, bandpass, polarizer, evaporation, sputtering, neutral density filter

\section{INTRODUCTION}

The EUMETSAT METOP-SG satellites host an earth observation Multi-viewing, Multi-channel and Multi-polarization Imager (3MI) to provide information on atmospheric aerosols and environment monitoring [1]. MetOp-SG is an ESA program, funded by the European Space Agency. To address multi-channel and multi-polarization properties, the imager (shown in Figure 1) is equipped with a filter wheel system (FWS, see Figure 2; [2]), positioned in front of two optical heads, composed by two concentric coronas of filter stack slots covering spectral channels distributed in VNIR (Visible and Near Infrared) range and SWIR (Short Wave Infrared) range, for a total of 13 different spectral channels. In each filter stack slot, an optical band-pass filters (BPF) is combined with an adjusted neutral density filter (NDF) and an optical path corrector (OPC). In addition, 9 of the 13 spectral channels are combined with linear polarizers (POLs) for 3 different polarization directions: $+60,0$, and -60 degrees. The other 4 channels are connected to polarizer substitutes. Those four types of optical elements (OEs): BPF, NDF, OPC, POL are combined to form stacks with a specific axial image shift comprising a tolerance below $10 \mu \mathrm{m}$.

This contribution addresses the manufacturing and characterization of the demanding dielectric optical coatings for the sophisticated BPFs developed by Optics Balzers. The BPFs are deposited by Plasma-Assisted Reactive Magnetron Sputtering (PARMS $[3,4]$ ) and cover the spectral range from $410 \mathrm{~nm}$ to $2130 \mathrm{~nm}$ with a bandwidth ranging between 10 and 40nm. The spectral channels are summarized in Table 1. The outstanding optical performance of the BPFs is ensured by the combination of the PARMS technology with a state-of-the-art optical broad-band monitoring system $(\mathrm{BBM})$ which allows in-situ process control as well as in-situ correction [5].

*andreas.rahm@opticsbalzers.com; phone +49 3641 3529587; fax +49 3641 352935; www.opticsbalzers.com 


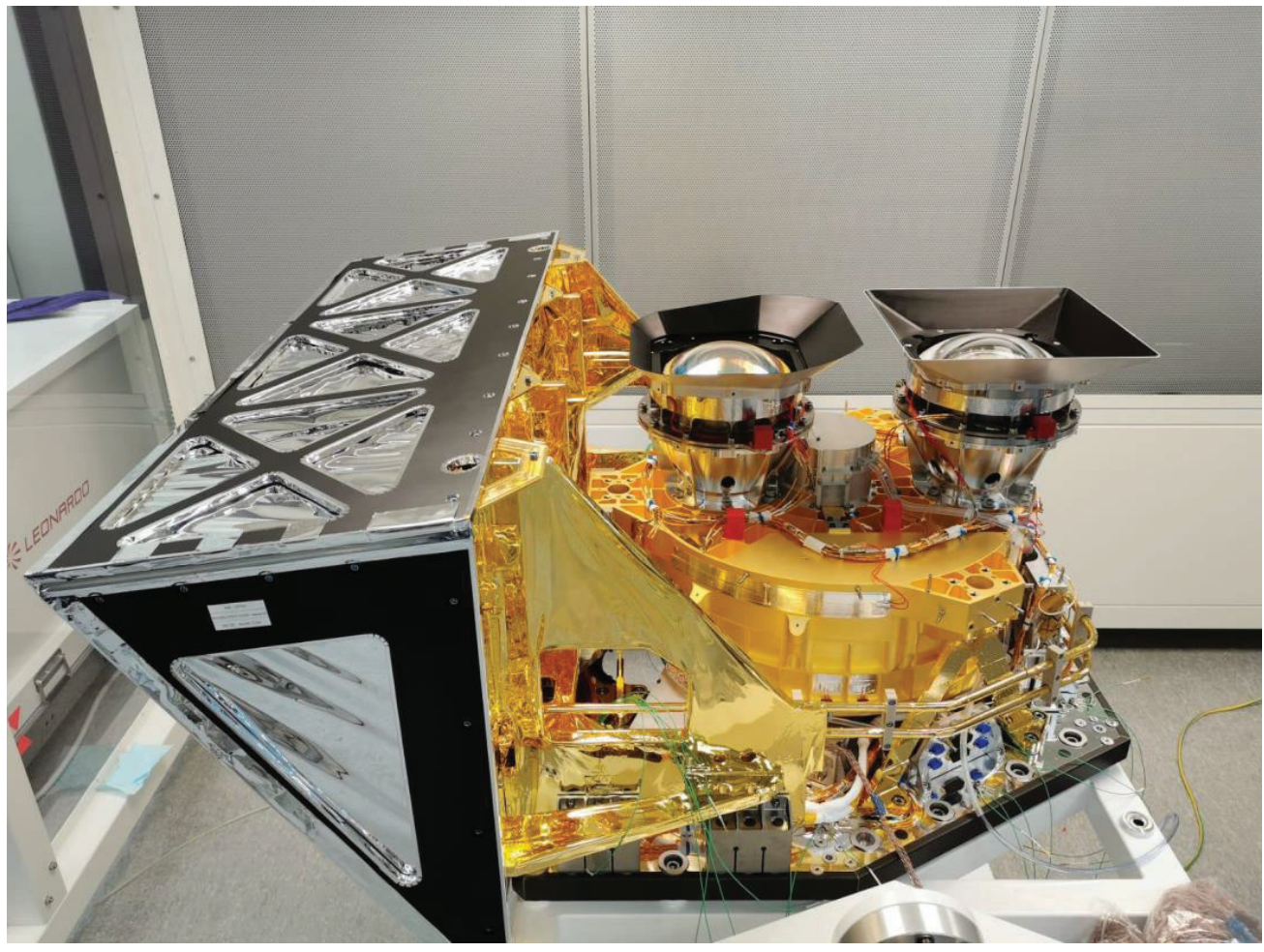

Figure 1: Instrument image (Courtesy of Leonardo).

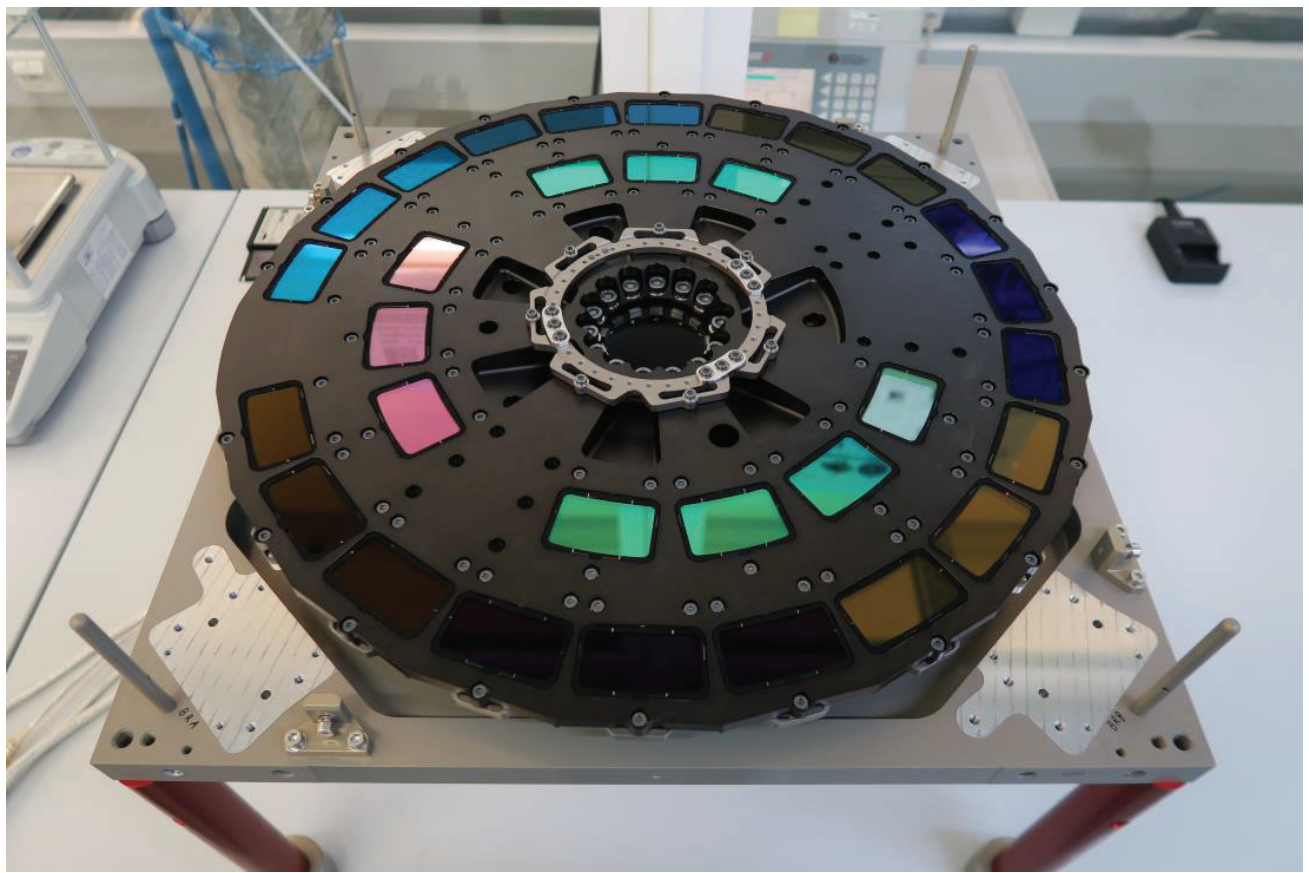

Figure 2. Filter Wheel Assembly (FWA) (Courtesy of RUAG [3]). 
Table 1. 3MI Spectral Channels

\begin{tabular}{|c|c|c|c|c|}
\hline Module & Channel & $\begin{array}{c}\lambda_{c} \\
(n m)\end{array}$ & $\begin{array}{c}\Delta \lambda \\
(\mathrm{nm})\end{array}$ & $\begin{array}{c}\text { Polarised } \\
\text { (Y/N) }\end{array}$ \\
\hline \multirow{9}{*}{ VNIR } & $3 \mathrm{MI}-2$ & 410 & 20 & $\bar{Y}$ \\
\hline & $3 \mathrm{MI}-3$ & 443 & 20 & $\bar{Y}$ \\
\hline & $3 \mathrm{MI}-4$ & 490 & 20 & $\mathrm{Y}$ \\
\hline & $3 \mathrm{MI}-5$ & 555 & 20 & $\mathrm{Y}$ \\
\hline & $3 \mathrm{MI}-6$ & 670 & 20 & 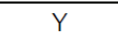 \\
\hline & $3 \mathrm{MI}-7$ & 763 & 10 & $\mathrm{~N}$ \\
\hline & $3 \mathrm{MI}-8$ & 765 & 40 & $\mathrm{~N}$ \\
\hline & $3 \mathrm{MI}-9$ & 865 & 40 & $\mathrm{Y}$ \\
\hline & 3MI-9a-VNIR & 910 & 20 & $\mathrm{~N}$ \\
\hline \multirow{4}{*}{ SWIR } & 3MI-9a-SWIR & 910 & 20 & $\bar{N}$ \\
\hline & $3 \mathrm{Ml}-10$ & 1370 & 40 & $Y$ \\
\hline & $3 \mathrm{Ml}-11$ & 1650 & 40 & $\mathrm{Y}$ \\
\hline & $3 \mathrm{MI}-12$ & 2130 & 40 & $\mathrm{Y}$ \\
\hline
\end{tabular}

\section{DESIGN AND MANUFACTURING APPROACH}

This chapter briefly describes the driving requirements for the 3MI BPF design and production.

\subsection{Deposition of multi-layer systems}

The coatings of the 3MI optical elements were performed by means of state-of-the-art Plasma-Assisted Reactive Magnetron Sputtering (PARMS) [3, 4]. All PARMS plants at OBJ are equipped with a sophisticated optical broad-band monitoring system (BBM) that allows the measuring of the optical thickness of the growing thin films directly on the rotating substrate holder with an approximated accuracy of $0.5 \mathrm{~nm}$ as minimum [5].

During the earlier Sentinel 2 project a study regarding PARMS suitability had been conducted. It could be shown that applied to complex self-blocking BPF the PARMS process is superior to the IAD (ion-assisted deposition) process in terms of spectral performance, uniformity, process stability, scattering performance and surface roughness.

OBJ used its Helios3 plant (Helios 800 by Bühler) to perform the optical coatings for the 3MI project.

As substrates for the BP Filters OBJ used standard fused silica SQ-1 for the VNIR spectral channels and infrared grade fused silica Infrasil 302 for the SWIR spectral channels. The BPF operate in the spectral channels reported in Table 1. They are manufactured with a bandpass coating on side 1 (facing the input light in the instrument) and a blocking or antireflection (AR) coating on side 2 (facing the detector).

\subsection{Optical design approach}

The 13 BP filters operating in the VNIR and SWIR spectral range are characterized by high constant transmittance in the pass region and broad blocking regions, comprising low levels of scattering. This requires a high-energetic deposition process and excellent thin-film growth control in the region of few $\AA$ (angstrom). The Plasma Assisted Reactive Magnetron Sputtering (PARMS) process with Broad Band Monitoring (BBM) is an adequate technological approach here.

Additional criteria, which drive the overall thickness of a BP coating, are the slope requirement and the rejection ratio, which defines the absolute level of the transmittance in the Out-of-Band spectral range. Furthermore, the requirement for low In- and Out-of-Band scattering into the forward direction of incoming light influences the thin-film design itself, the concept of coating combination and filter orientation as well as the choice of coating materials. 
OBJs realized the requested spectral performance with a certain optimum number of layers to be coated and minimal total thickness of the coatings.

This was motivated by:

- the general manufacturing process risk,

- allowing for a good controllability of manufacturing,

- low production tolerances during the manufacturing process,

- contamination risk during long lasting coating processes and

- the long-term environmental stability of the component(s).

From OBJs practical experience in maintaining opto-mechanical properties at a reasonable level demonstrated in the past, a restriction of the total thickness to about $30 \mu \mathrm{m}$ of a single coating was targeted. The following assessment describes the criteria, which were responsible for the filter design complexity and overall-thickness.

It evolved that the realization of such coatings - especially with the required homogeneity - depends on a stable and extremely deterministic deposition process. The individual layers are allowed to comprise an absolute error-level of few angstroms only. There are the following two approaches for the BPF designs (see Table 2).

Approach 1: is to design a "self-blocking" coating on one side (where all spectral requirements including full range blocking are fulfilled with this coating) and an AR-coating on the back side.

Approach 2: is to split the spectral function between the two sides of the substrate. Classically, this can be achieved by combining long and short pass filters to the required band pass performance. With respect to reduce large angle scatter and ghost effects OBJ's approach is to split the spectral function into a band-pass filter coating with a surrounding blocking zone on one side and to the remaining blocking on the other side. Both layer stacks must be designed to minimize bending effects.

Table 2. Possible design approaches

\begin{tabular}{|c|c|c|}
\hline name & approach 1 & approach 2 \\
\hline type & self-blocking design & split design \\
\hline $\operatorname{side} \mathrm{A}$ & bandpass and full blocking & $\begin{array}{l}\text { bandpass including some blocking } \\
\text { function around passband }\end{array}$ \\
\hline side $\mathrm{B}$ & $\mathrm{AR}$ & wide range blocking \\
\hline pro & $\begin{array}{l}\text { reduced risk of large angle scattering (LLAS) } \\
\text { especially for lower wavelength (VNIR) }\end{array}$ & $\begin{array}{l}\text { PARMS technology produces low scatter } \\
\text { levels in general }\end{array}$ \\
\hline cons & $\begin{array}{l}\text { One coating is almost twice as thick as for } \\
\text { approach 2, which increases process and } \\
\text { contamination risk (especially SWIR coating } \\
\text { affected), but can be used to build up slope } \\
\text { steepness }\end{array}$ & $\begin{array}{l}\text { less design freedom because of required } \\
\text { compensation functionality, slope } \\
\text { steepness defines thickness of BPF-side } \\
\text { coating }\end{array}$ \\
\hline
\end{tabular}

With respect to the extremely demanding level of requirements OBJ had chosen the following approaches to realize the BP filter coatings:

The VNIR filters are designed as single sided self-blocking filters based of $\mathrm{Ta}_{2} \mathrm{O}_{5} / \mathrm{SiO}_{2}$ dielectric stacks with a channel specific anti-reflective coating on side 2. This ensured the required low level of scatter and high transmittance for all channels. With around $20 \mu \mathrm{m}$ total thickness and up to 200 layers the rejection requirements are fulfilled, and the slope is as small as achievable with this total thickness.

The SWIR filters consist of a bandpass filter on side 1 and an additional block filter on side 2. Both coatings consist of $\mathrm{Nb}_{2} \mathrm{O}_{5} / \mathrm{SiO}_{2}$ dielectric stacks, which comprise a sufficient low level of in-and out of band scatter in this configuration and this wavelength region. The thickest coating is for spectral channel $3 \mathrm{MI}-10$ at $1370 \mathrm{~nm}$ with $27 \mu \mathrm{m}$ and $26 \mu \mathrm{m}$ on the both sides. 


\subsection{Spectral performance of optical design}

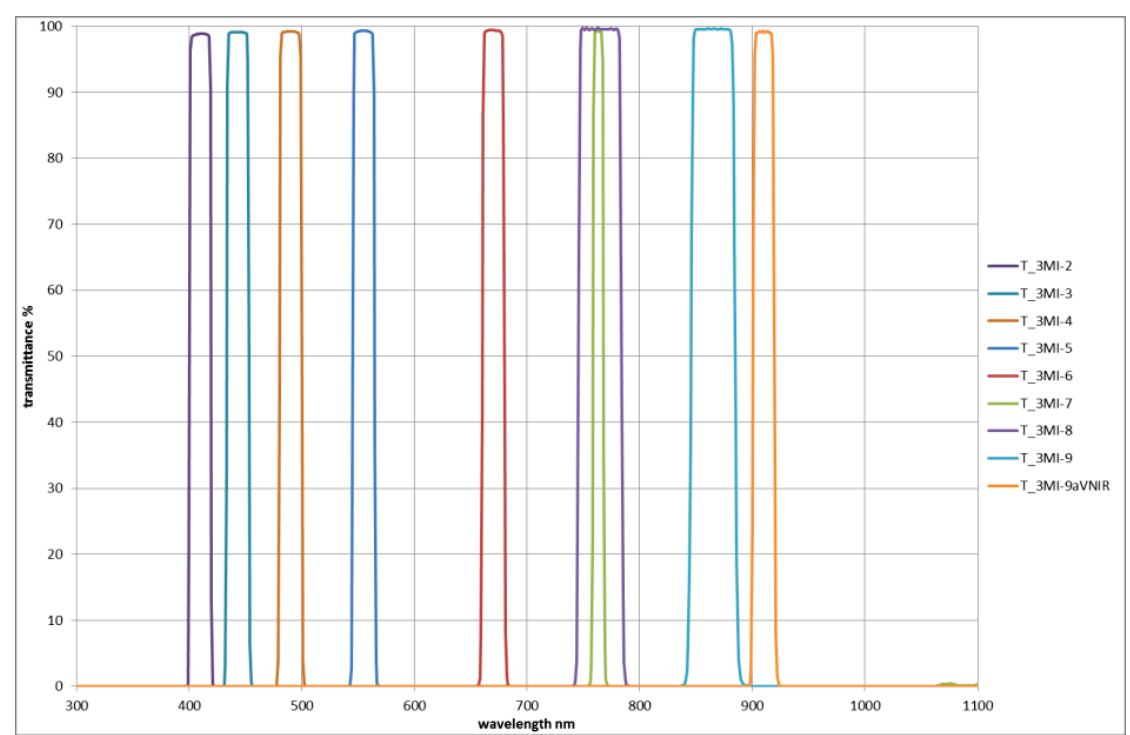

Figure 3: VNIR channel pass band (design)

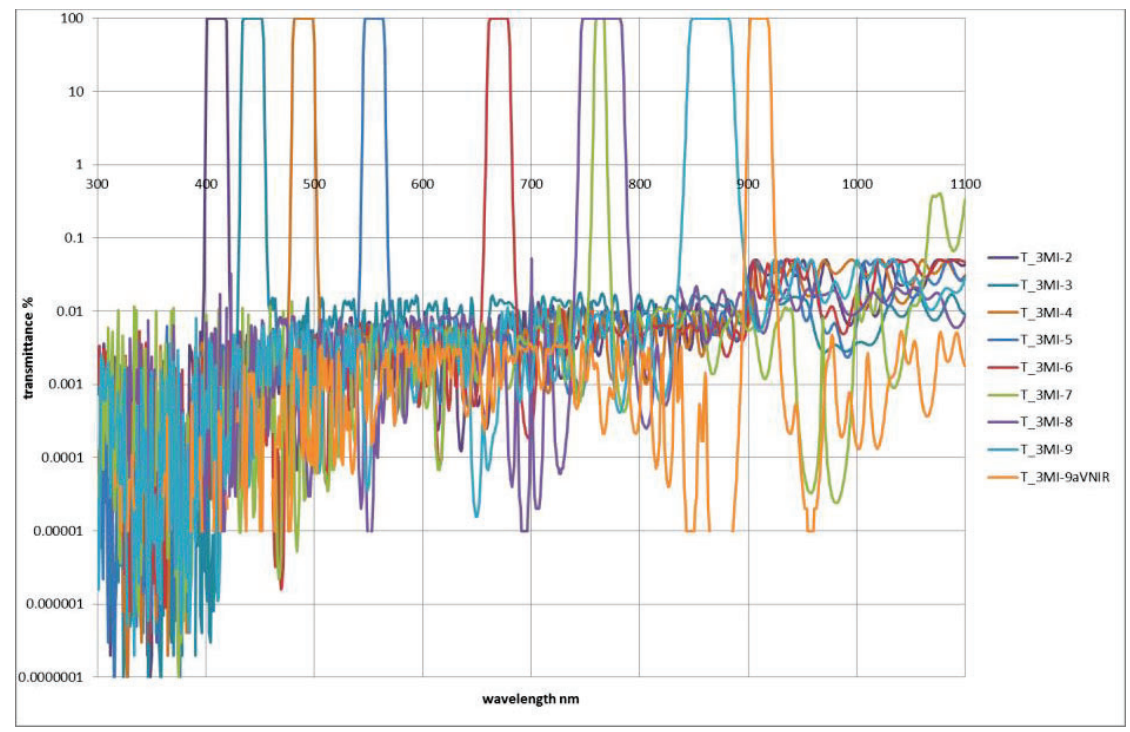

Figure 4: VNIR channel blocking (design) 


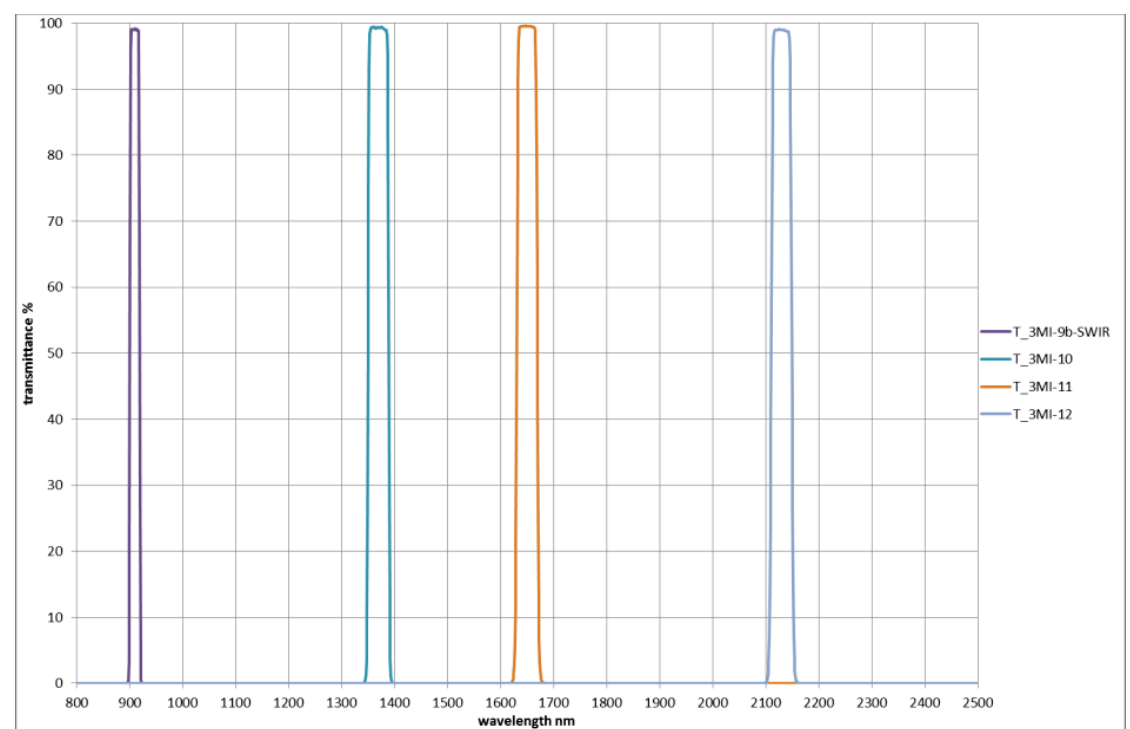

Figure 5: SWIR pass band (design)

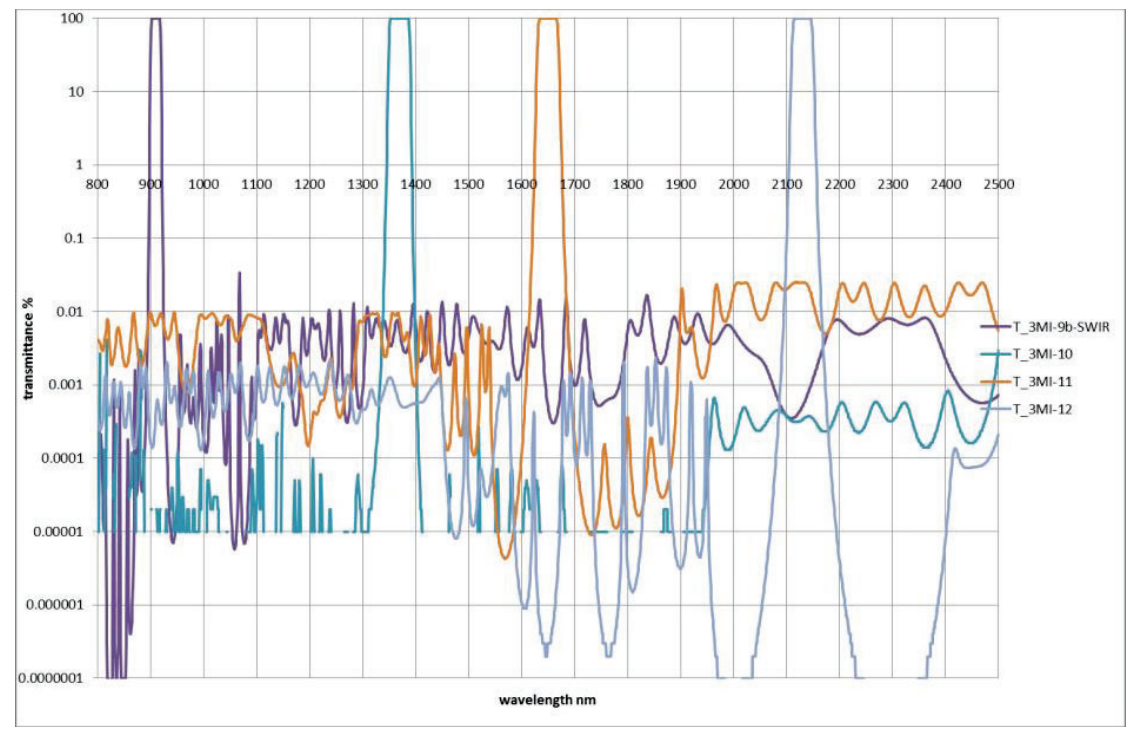

Figure 6: SWIR channel blocking (design)

Figure 3 to Figure 6 present an overview of the spectral performances of all 3MI-channels. The specific designs were chosen to fulfil a pre-defined spectral shape template (see example in Figure 7). Main-drivers for the complexity, i.e. number of layers and also the total thickness of the required coatings were the width and depth of the spectral blocking range, the slopes of the bandpass-edges and the In-Band Equivalent Transmittance/Reflectance while partly being related. The designs are also optimized with respect to the in-band retardance. 


\section{CHARACTERIZATION OF 3MI BP FILTERS}

This section contains a characterization of the 3MI BPFs in terms of their spectral performance and surface roughness.

\subsection{Transmission and block measurements}

The spectral characterization of the BP filters was done using spectrometers Perkin Elmer Lambda 950/1050, which are double beam, double monochromator, ratio recording UV/Vis/NIR spectrophotometers.

Spectral uniformity measurements were done using an adjustable support. It is equipped with an aperture (hole or slit) for the limitation of the spectrophotometer beam. This slit limits the incoming $(4 \mathrm{x} 8) \mathrm{mm}^{2}$ beam down to $(0.4 \mathrm{x} 5) \mathrm{mm}^{2}$ to allow a measurement within the required sample aperture. Both, beam slit and sample holder are independently adjustable in three directions ( $\mathrm{x}-\mathrm{y}$-z-adjustment) to get maximum signal for the transmission.

Transmission measurements for 4 different 3MI spectral channels are depicted in $\quad$ Figure 7 and Figure 8. There are 9 different curves shown in each of the graphs representing measurements on 9 different lateral points across one single sample. The required spectral template is also shown (black and grey lines). It can be seen that the filters achieve very high transmission levels $>92 \%$ with steep slopes. The spectral channel the homogeneity is challenging to achieve (especially e.g. 3MI-12 in Figure 8). The PARMS deposition method is ideal for such overall high spectral performance requirements.

The slope of the BPF varied between $2.5 \mathrm{~nm}$ and $6.5 \mathrm{~nm}$ depending on the wavelength. A channel center non-uniformity of $\pm 0.5 \mathrm{~nm}(3 \mathrm{MI}-2)$ to $\pm 2.2 \mathrm{~nm}$ (3MI-12) was achieved. The typical In-Band equivalent transmittance end-to-end was $>0.92$.
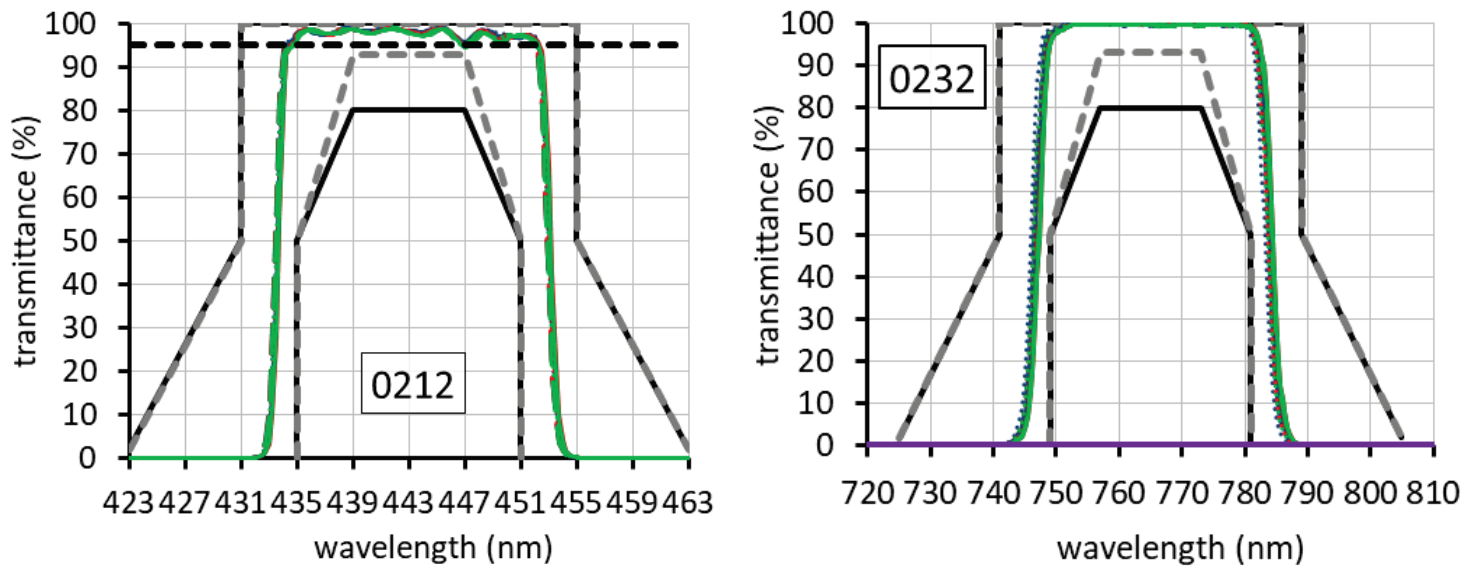

Figure 7: 3MI-3 (left) and 3MI-8 (right). 

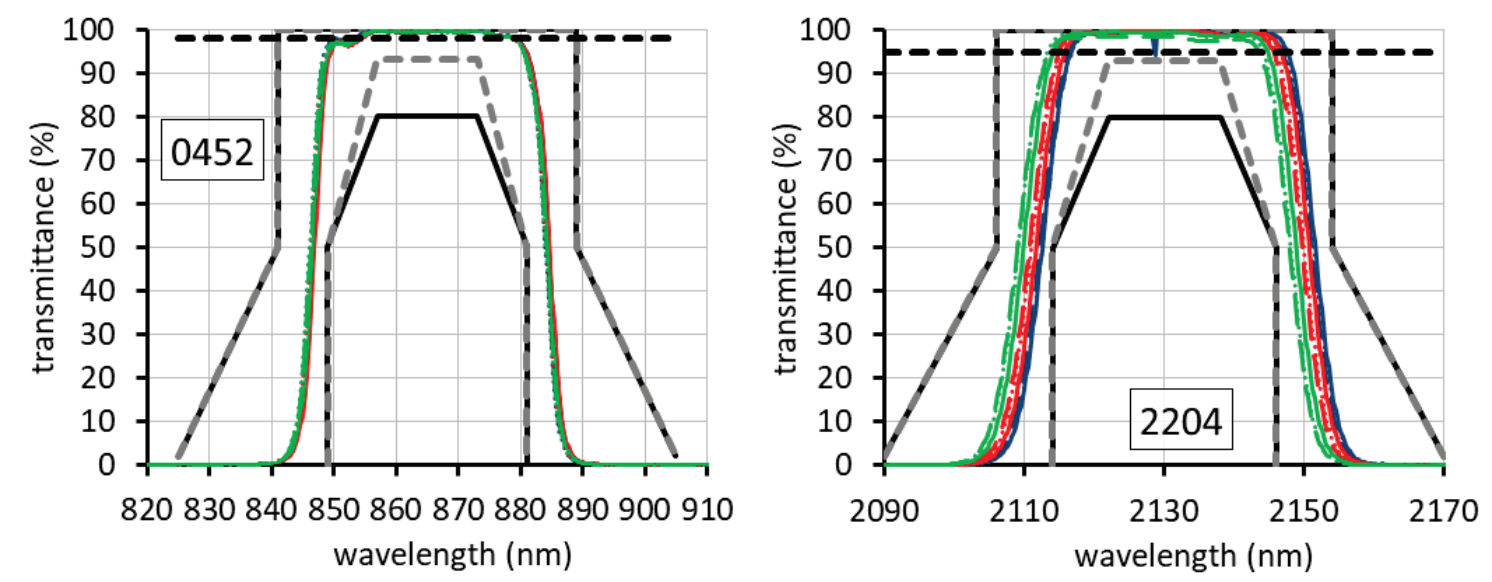

Figure 8: transmission spectra of 3MI-9 (left) and 3MI-12 (right)

Besides a detailed in-band spectral characterization, also the out-of-band blocking was measured. Figure 9 (3MI-2) and Figure 10 (3MI-8) show detailed block measurements of 2 selected 3MI channels. The out-of-band integrated signal OB

$$
O B=1-\frac{\int_{\lambda_{c}-\Delta \lambda}^{\lambda_{c}+\Delta \lambda} k_{F S}(\lambda) T_{F S}(\lambda) d \lambda}{\int_{\lambda_{\min }}^{\lambda_{\max }} k_{F S}(\lambda) T_{F S}(\lambda) d \lambda}
$$

was calculated from the block measurements taking into account 5 different illumination scenarios which are relevant for the MetOp second generation 3MI mission [1]. This was done using corresponding spectral weighting factors $\mathrm{k}_{\mathrm{FS}}$ for sun, vegetation, clouds, ocean and desert, respectively. The integrated signal was typically in the range 0.0005 to 0.01 depending of spectral channel and illumination scenario.

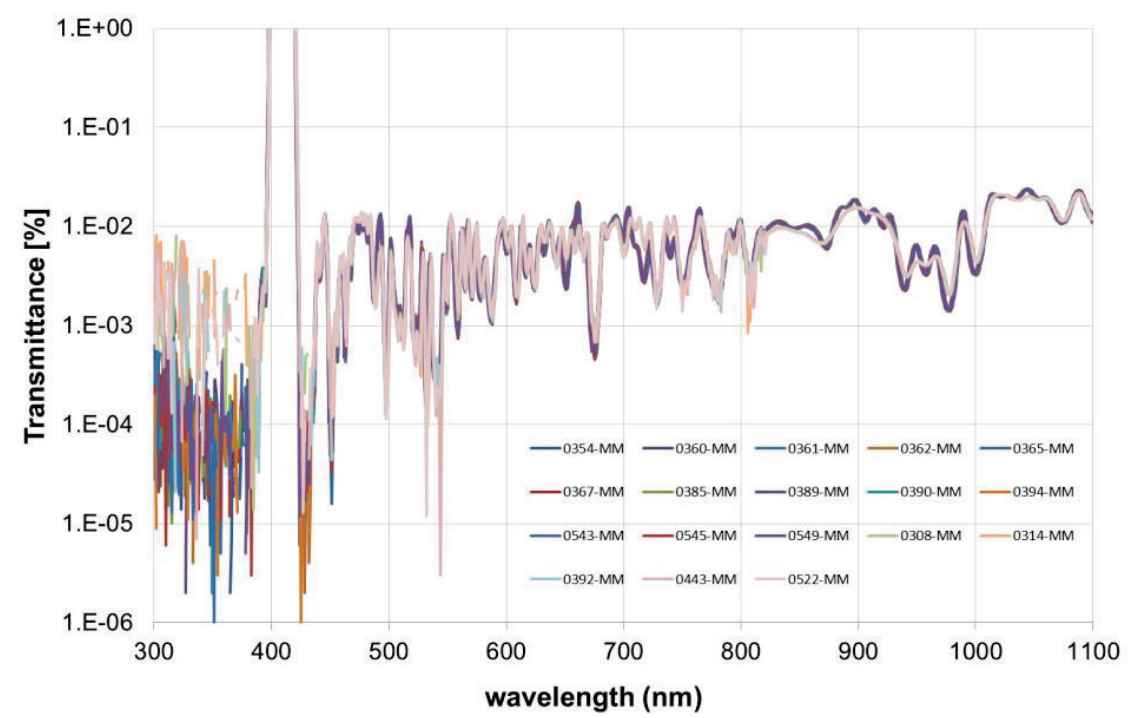

Figure 9: Transmittance block measurements of all samples for 3MI-2. 


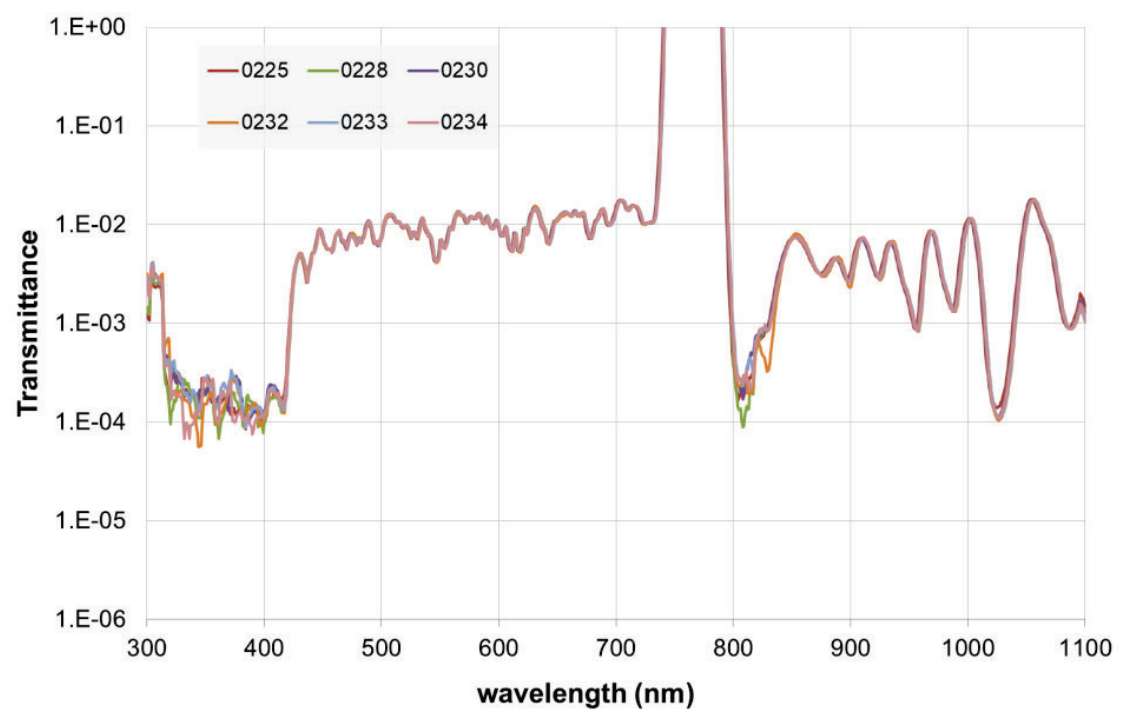

Figure 10: 3MI-8 Central transmittance block measurements of 6 BPFs.

\subsection{Straylight performance}

The total integrated scatter (TIS) was measured with a $150 \mathrm{~mm}$ integrating sphere accessory for the Lambda 1050 spectrometer at Optics Balzers. This sphere is equipped with an UV/Vis/NIR (PM/InGaAs) detector module, a Spectralon ${ }^{\circledR}$ sphere with an $8^{\circ}$ sample and reference reflectance ports and $0^{\circ}$ transmittance port. The wavelength range goes from 200 to $860 \mathrm{~nm}$ by photomultiplier and from 860 to $2500 \mathrm{~nm}$ by a Peltier-cooled wide range InGaAs detector. The spectral resolution is $\leq 0.05 \mathrm{~nm}$ (UV-VIS) and $\leq 0.2 \mathrm{~nm}$ (NIR).

TIS spectra for 3MI-8 and 3MI-9aSWIR are shown in Figure 11 and Figure 12, respectively. The total in-band scattering and out-of-band scattering was also calculated using the weighting factors $\mathrm{k}_{\mathrm{FS}}$ and was typically $<0.5 \%$ for all illumination scenarios.

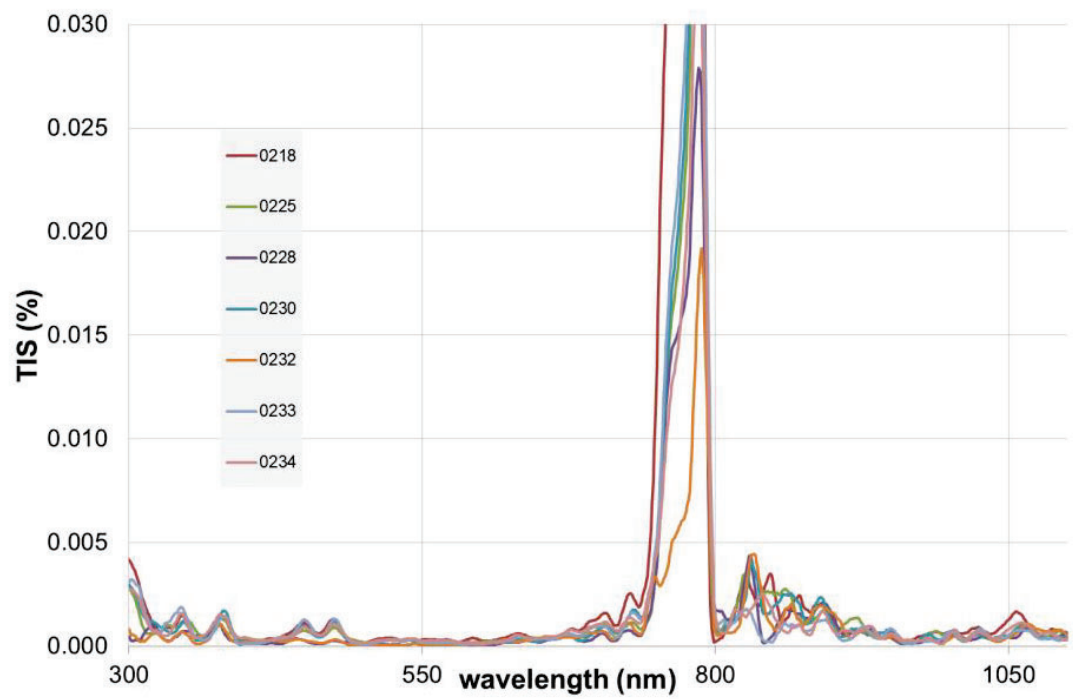

Figure 11: TIS Measurement of 7 different samples (channel 3MI-8) 


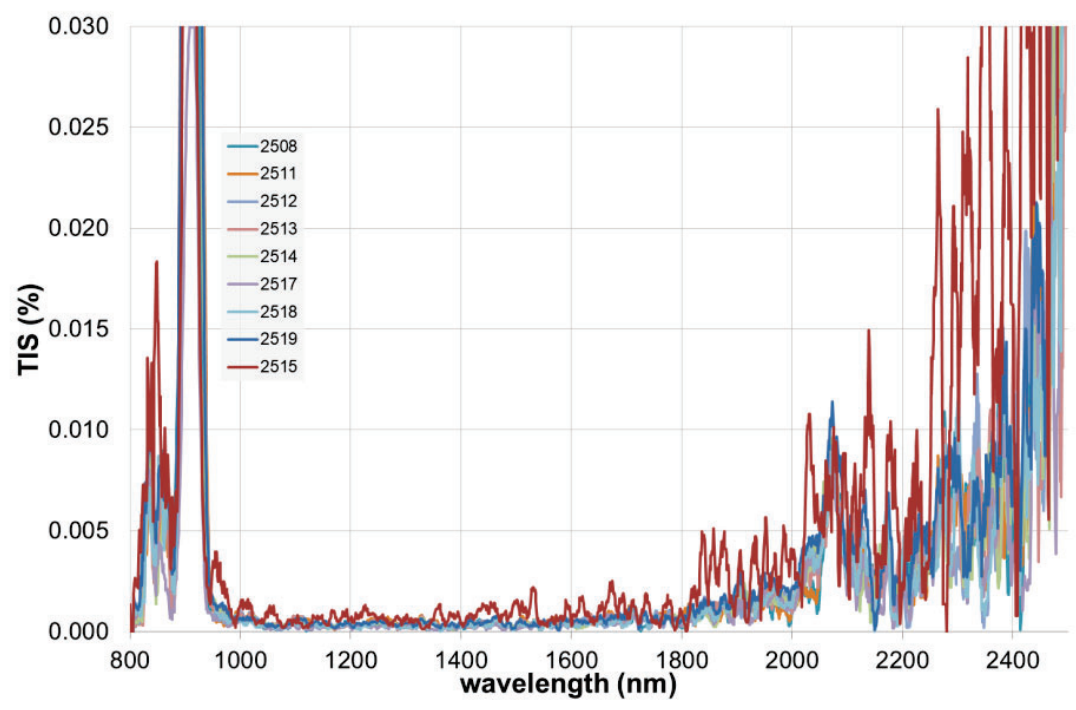

Figure 12: 3MI-9aSWIR TIS measurement. 9 different samples are shown.

\subsection{Further scattering characterization - BTDF measurements}

The Bidirectional Transmittance Distribution Function (BTDF) for each BPF channel on selected samples has been measured to gain further insight into the scattering properties. For each channel, the in-band scattering properties at the central wavelengths of the different transmittance bands as well as the out-of-band scattering characteristics is characterized. For this, the light scattering system MLS-1600 is used, which was developed at external measurement contractor Fraunhofer IOF in Jena based on an optical parametric oscillator (OPO). The system allows changing the wavelength continuously from $193 \mathrm{~nm}$ to $1750 \mathrm{~nm}$. [6]

The BTDF, is defined as the ratio of the transmitted radiance in the direction described by the polar, $\Theta_{\mathrm{s}}$, and azimuthal scattering angle, and the incident irradiance. The light scattering measurements were performed with the following parameters. Further details can be found in [6].

The chosen measurement wavelengths are the central wavelength of the BPF, the lower band edge of the filter, and outof-band (typically 10 to $20 \mathrm{~nm}$ away from the lower band edge). The angle of incidence is $0^{\circ}$ and the polar scattering angle ranged from: $+90^{\circ} \ldots+270^{\circ}$ ( step size $0.5^{\circ}$ ). The direction of the transmitted beam is at $180^{\circ}$ and the azimuthal scattering angle at $0^{\circ}$. The incident polarization is s-polarized. The incident light is focused onto the detector aperture of the system in order to enable the determination of the near angle scattering of the sample even in the presence of the incident beam. 


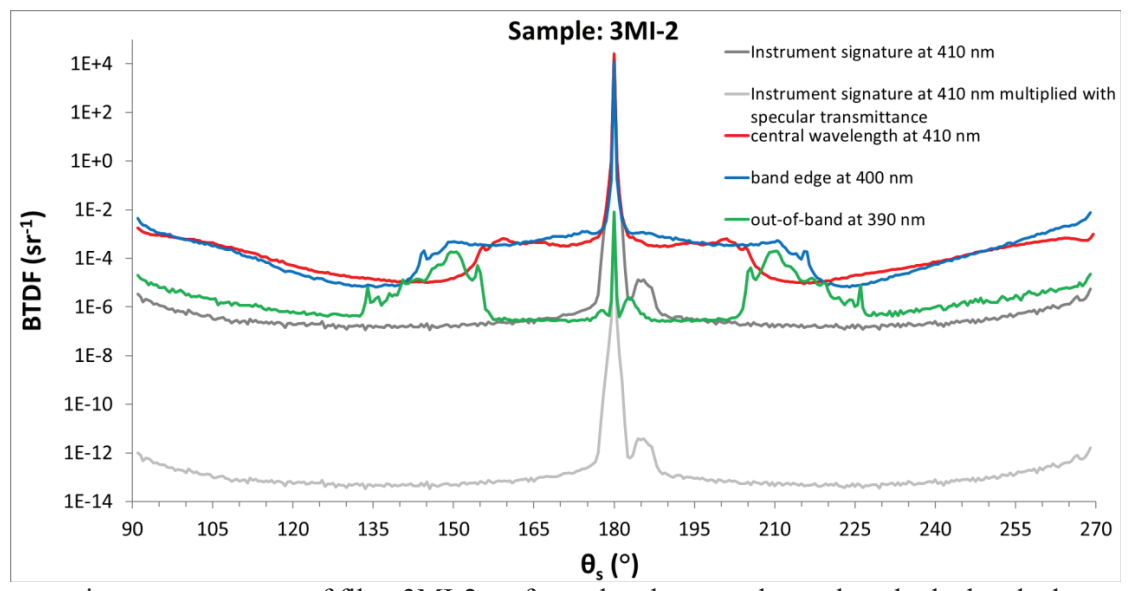

Figure 13. Light scattering measurements of filter 3MI-2 performed at the central wavelength, the band edge, and out-of-band. The scattering angle $\Theta_{\mathrm{s}}=180^{\circ}$ corresponds to the specular transmitted beam direction.

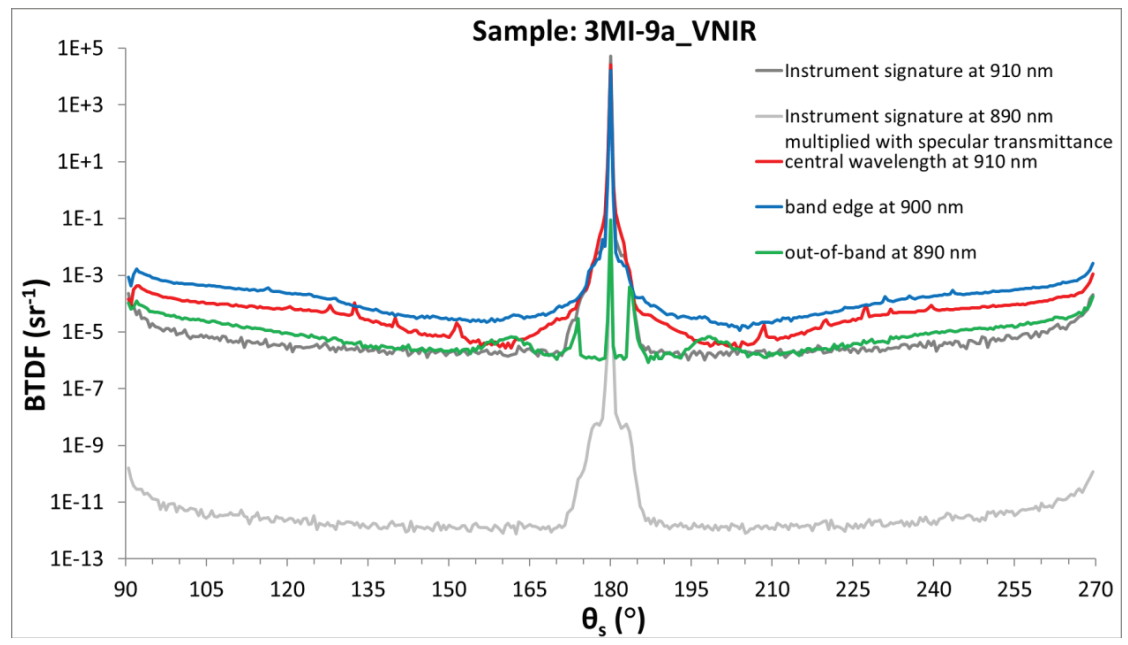

Figure 14. Light scattering measurements of filter 3MI-9a_VNIR performed at the central wavelength, the band edge, and out-ofband. The scattering angle $\Theta_{\mathrm{s}}=180^{\circ}$ corresponds to the specular transmitted beam direction.

Figure 13 and Figure 14 show examples of BTDF measurements for spectral channels 3MI-2 and 3MI-9a_VNIR, respectively. In addition to the measurement of the filters, the instrument signature is plotted, which is a light scattering measurement without a sample. Thus, it represents the intrinsic light scattering of the measurement system, which is several orders below the scattering from the sample. For the out-of-band measurements, the instrument signature is multiplied by the specular transmittance of the sample, as this is also the case for the actual performed measurements in which the intrinsic scattering of the instrument has to pass the filter and is thereby reduced in intensity.

The scattering behavior at the central wavelength and the band edge is similar, indicating resonant scattering within the two multilayer stacks up to a scattering angle of $\left|\Theta_{\mathrm{s}}-180^{\circ}\right| \sim 30^{\circ}$ and a scattering level of BRDF $\sim 1 \times 10-4 \mathrm{sr}^{-1}$. This resonant scattering is more pronounced for the band edge than at the central wavelength.

For the out-of-band measurement, the scattering around the transmitted beam falls off quickly due to the blocking behavior of the coatings. At $\left|\Theta_{\mathrm{s}}-180^{\circ}\right| \sim 40^{\circ}$, a small resonant scattering peak can be observed in Figure 13.

Only close to the specular transmitted beam a higher scattering signal can be observed which is also the case for filters from channel 3MI-9a_VNIR, as shown in Figure 14. 


\subsection{Surface roughness characterization}
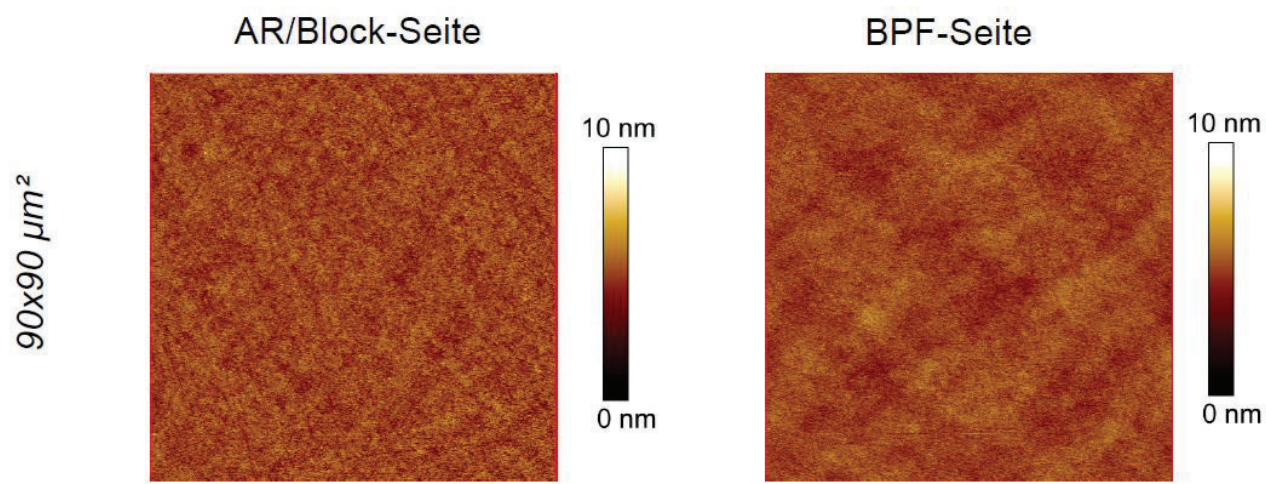

$S_{q}=0,59 \mathrm{~nm}$

$\mathrm{S}_{\mathrm{q}}=0,48 \mathrm{~nm}$

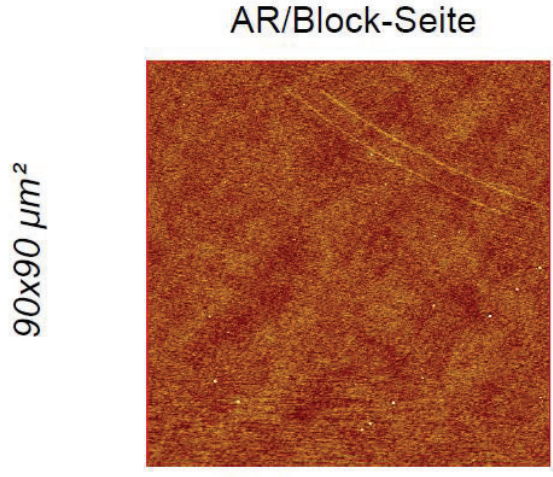

$\mathrm{S}_{\mathrm{q}}=0,67 \mathrm{~nm}$

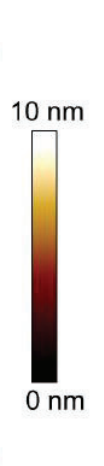

Figure 15: AFM images of typical 3MI BPF surfaces; top: 3MI-2; bottom: 3MI-11.

The 3MI BPFs were characterized by atomic force microscopy (AFM) using a Bruker DimensionIcon instrument at the Fraunhofer IOF in Jena. Figure 15 shows AFM images of typical BP filter surfaces for 2 selected spectral channels (3MI2 top, 2MI-11 bottom). The area of the measurement is 90x90 $\mathrm{m}^{2}$. Table 3 summarizes roughness values of 6 different spectral channels. The surfaces on both sides of the optical elements are very smooth with rms surface roughness typically below $1 \mathrm{~nm}$, independent from thin-film complexity. Low surface roughness is usually associated with less straylight and better environmental stability.

Table 3: coated BPF roughness values for Sides A and B.

\begin{tabular}{|c|c|c|c|}
\hline Substrate ID & channel & Side A [nm] & Side B [nm] \\
\hline Requirement & & $\begin{array}{l}<1.0 \mathrm{~nm} \text { VNIR } \\
<1.5 \mathrm{~nm} \text { SWIR }\end{array}$ & $\begin{array}{l}<1.0 \mathrm{~nm} \text { VNIR } \\
<1.5 \mathrm{~nm} \text { SWIR }\end{array}$ \\
\hline 0355 & $3 \mathrm{MI}-2$ & 0.59 & 0.48 \\
\hline 1501 & $3 \mathrm{MI}-4$ & 0.68 & 0.75 \\
\hline 0201 & $3 \mathrm{MI}-7$ & 0.67 & 0.6 \\
\hline 0425 & $3 \mathrm{MI}-9$ & 0.69 & 0.33 \\
\hline 2518 & 3MI-9aSWIR & 1.1 & 0.95 \\
\hline 2015 & 3MI-11 & 0.67 & 0.54 \\
\hline
\end{tabular}




\section{CONCLUSION}

The optical design approach of the 3MI BPFs was discussed in detail. The produced filters were characterized by transmission, blocking and straylight measurements. They exhibit steep slopes $(2.5 \mathrm{~nm}$ to $6.5 \mathrm{~nm}$ depending of channel), high transmittance (>92\%), superior out-of-band blocking and very good lateral homogeneity as well as high cleanliness requirements. We presented a detailed analysis of the optical properties in terms of BPF shape. In-band and out-of-band scattering under different illumination scenarios relevant to the 3MI project were discussed. For the channels $3 \mathrm{MI}-2$ to 3MI-11 the in-band scattering properties at the central wavelengths of the different transmittance bands as well as the out-of-band scattering characteristics were characterized by angle resolved light scattering measurements (BTDF). Surface roughness was analyzed by AFM and shows very smooth roughness values well below $1 \mathrm{~nm}$ rms.

In total, more than 550 optical elements (BPFs, polarizers, neutral density filters and optical path correctors) have been supplied to the $3 \mathrm{MI}$ project by Optics Balzers. All optical components of the 3MI stacks exhibit excellent environmental stability and the space qualification process was successfully passed.

\section{ACKNOWLEDGEMENTS}

The work presented was done in the framework of the ESA MetOp-SG program, funded by the European Space Agency. OBJ thanks ESA, AIRBUS DS, LEONARDO and RUAG Space for selection and cooperation during the development and $3 \mathrm{MI}$ project. The cooperation with Fraunhofer IOF concerning the BTDF and AFM measurements is highly acknowledged.

\section{REFERENCES}

[1] Manolis, I., Caron, J., Grabarnik, S., Bézy, S., Betto, M., Barré, H., Mason, G., Meynart, R., "The MetOp second generation 3MI mission", Proc. SPIE 10564, International Conference on Space Optics - ICSO 2012, 105640A (2017).

[2] Scheidegger, N., Vedovati, F., Frei, P., Lang, A. , Knodel, T. , Holland, M. , Anderson, M.J., „Filter wheel assembly: a long life space-mechanism with hard mounted bearings", Proc. 18. ESMATS (2019).

[3] Scherer, M., Pistner, J., Lehnert, W., "Innovative production of high-quality optical coatings for applications in optics and opto-electronics", 47th Annual Technical Conference Proceedings of the Society of Vacuum Coaters, $179,(2004)$.

[4] Weber, T., Lappschies, M., Jakobs, S., "Manufacturing of high-performance VIS-NIR beam splitters by plasma assisted thin film deposition technologies," Proc. SPIE 10691, 106911A, (2018).

[5] Ristau, D., Ehlers, H., Gross, T., Lappschies, M., "Optical broadband monitoring of conventional and ion processes," Applied Optics, 45, 1495-1501 (2006).

[6] Schröder, S., Finck, A., Katsir, D., Zeitner, U., Duparré. A., „, Light scattering characterization of optical components: BRDF, BTDF, and scatter losses", Proc. SPIE 9272, Optical Design and Testing VI, 927202 (2014) 